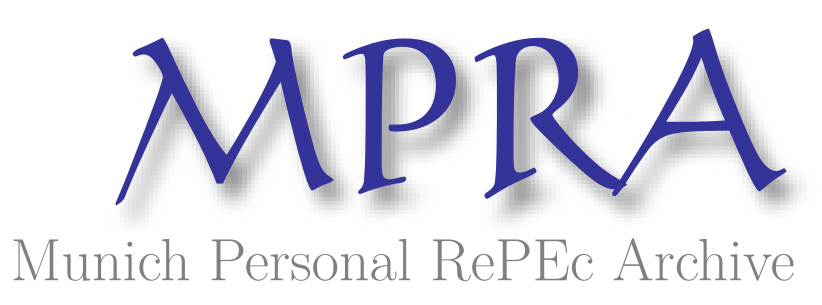

\title{
Alternative Measures of Rent Content
}

Londero, Elio

1999

Online at https://mpra.ub.uni-muenchen.de/85339/

MPRA Paper No. 85339, posted 25 Mar 2018 14:49 UTC 


\title{
ALTERNATIVE MEASURES OF RENT CONTENT
}

\author{
by Elio Londero *
}

June, 1999

\begin{abstract}
This paper reviews three methods for measuring the rent content of output, shows the sources of differences among them, establishes a priori orderings among primary input ratios calculated under these methods, and discusses their advantages and disadvantages for applied work.
\end{abstract}

J.E.L. Classification: D57, F10

Keywords: factor content, rent content, natural-resource content, input-output

* Inter-American Development Bank. Opinions expressed in this paper are those of the author and are not intended to represent the views of the Bank. Comments by S. Teitel and two anonymous referees, and valuable help from Pablo Londero are gratefully acknowledged. The author remains solely responsible for the result. This is an Accepted Manuscript of an article published by Taylor \& Francis in The International Trade Journal on 29 Oct 2010, available online: http://www.tandfonline.com/doi/abs/10.1080/088539099271928. 


\title{
ALTERNATIVE MEASURES \\ OF RENT CONTENT
}

\author{
by Elio Londero ${ }^{1}$
}

\section{Introduction}

The primary-input ("factor") endowments of a country are expected to be crucial determinants of the composition of primary-input "services" embodied in its trade flows. Primary-input endowments thus become an important determinant of the product composition of trade flows, since the range of available efficient techniques is narrow for most products, i.e., adjustment to changes in relative prices of inputs through substitution is limited. For that reason, many empirical studies have been conducted to study the relationship between primary-input endowments and the primary-input content, and/or the product composition, of trade in goods. Following two pioneering articles by Leontief $(1953,1956)$ on the labor and capital content of United States foreign trade, Vanek (1963) called attention to natural resource endowments, and consequently to the rent content of industry output. A significant part of the literature that followed was based on estimating the total primary-input composition of industrial output using input-output (IO) techniques. ${ }^{2}$ This approach requires a measure of direct primary-input use that can be translated into, or associated with an entry in the I-O table. In particular, a measure of the value of the direct use of natural resources has to be defined, and several alternatives have been proposed to that effect. This paper reviews those proposals, it formulates them on a comparable basis, and shows the effects of alternative methods on the ensuing primary input ratios.

Vanek proposed using the "value of resource products" consumed in the

${ }^{1}$ Inter-American Development Bank. Opinions expressed in this paper are those of the author and are not intended to represent the views of the Bank. Comments by S. Teitel and two anonymous referees, and valuable help from Pablo Londero are gratefully acknowledged. The author remains solely responsible for the result.

${ }^{2}$ Deardorff (1984) and Leamer and Levinsohn (1994) review studies on the factor content of trade. 
production process as an indicator of the direct rent content, that is, of the rent payments made by the activity. He defined resource products (RP) as "all commodities whose productive process makes direct use of natural resources, and for which values of output are currently recorded. Thus wheat grain is a resource product, while wheat flour is not, since it does not use land as a direct input" (p. 10). Note that the definition is not entirely satisfactory, since what is meant by "direct" is not clear. The mill also uses land directly, since buildings would occupy a piece of land, although the rent content of its output would be insignificant. On the other hand, if by direct it is meant that plants have roots, cattle raising would not be a "resource product." In the end, the definition of a resource product is arbitrary, although based in an intuitively gauged direct rent content. The same arbitrariness in defining the activities producing outputs with a high rent content is shared by all proposals discussed in this paper.

Assuming for the sake of simplicity that natural resources are used only in RP activities (RPA), Vanek proposed to measure the natural resource content of traded goods using the total RP requirements to produce one unit of exports or imports. This paper will show that Vanek's approach underutilizes the available information for RPA and forces the analyst to omit information or to incur in double counting. To solve this problem, Postner (1975) proposed imputing a constant "resource factor" coefficient to all RPA. Thus, rent content would be proportional to RP content, but the information on current costs of RPA would not be lost. ${ }^{3}$ An alternative method, to use the gross operating surplus of the resource-product activity (GOSRPA) as a proxy for its direct rent content, was proposed by Londero (1998). ${ }^{4}$ This method also makes full use of the information on current costs of RPA, and would capture the variability in rent coefficients if it is reflected in the variability of the gross operating surplus of the RPA.

${ }^{3}$ See Postner (1975, pp. 11-12).

${ }^{4}$ For an application of this method see Londero and Teitel (1996), and Londero, Teitel et al. (1998). 


\section{Comparing Methods}

According to Vanek's definition, the natural resource content of activity $j$ 's output would be estimated by

$$
r_{N j}=\sum_{i \in N} r_{i j}
$$

where $i \in N$ are the RP, and $\left[r_{i j}\right]=(\mathbf{I}-\mathbf{A})^{-1}$ is the Leontief inverse, as if "resource products were made of land alone" (Vanek, 1963, p. 11). Thus, primary input content for nonRP could be calculated exclusively from nonresource inputs, that is

$$
\begin{aligned}
& l_{j}^{*}=\sum_{i \notin N} l_{i} r_{i j} \\
& k_{j}^{*}=\sum_{i \notin N} k_{i} r_{i j}
\end{aligned}
$$

where $l_{i}$ and $k_{i}$ are labor and capital use coefficients. ${ }^{5}$ As a result, labor and capital contents will be underestimated, affecting intercountry comparisons among countries with different natural resource endowments.

Alternatively, labor and capital requirements may be calculated from all inputs, that is

$$
\begin{aligned}
& l_{j}^{*}=\sum_{i} l_{i} r_{i j} \\
& k_{j}^{*}=\sum_{i} k_{i} r_{i j}
\end{aligned}
$$

In such case, only a certain proportion $\rho_{j}$ of total RP requirements $r_{N j}$ would have to be imputed as rent. Otherwise, there would be some double counting, since indirect labor and capital requirements of resource products would be later counted again as part of the value of the resource-product input. If reproducible capital use coefficients $k_{j}$ could be estimated for RPA, then, direct rent coefficients $\rho_{j}$ could also be estimated by imputing capital-use coefficients and obtaining rent coefficients as a residual. This would be the preferred alternative whenever these estimates are possible. In practice, however, the cost

\footnotetext{
${ }^{5}$ Sometimes capital-output ratios are used instead.
} 
of estimating capital-use and rent coefficients exceeds research budgets. ${ }^{6}$ For that reason, such estimates are usually not feasible routes for the applied researcher.

Within the scope of these two approaches, the analyst has to assume either that resource products are exclusively made of natural resources, losing the information on current inputs used in RPA, or equal rent coefficients for all RPA. This method of imputing a constant rent coefficient to all resource-product activities was followed by Postner (1975), who assumed that "the direct natural resource factor coefficients are positive and equal for all natural resource product industries" (p. 11). ${ }^{7}$

An alternative method is based on using the total primary-input content of activity ouptut, that is

$$
\mathbf{F}^{*}=\left[f_{h j}^{*}\right]=\mathbf{F}(\mathbf{I}-\mathbf{A})^{-1}
$$

where $\mathbf{F}=\left[f_{h j}\right]$ is the matrix containing the direct value requirements of primary input $h$ per unit value of output $j$. Starting from (4), Londero (1998) proposed using the gross operating surplus of the RPA (GOSRPA) as a proxy for its direct rent content.

These two methods have the advantage of taking into account differences in primary-input content originating in the differences in the current-input content of the RP. Such advantage could be very important when modern and traditional production techniques coexist, since modern techniques may be more intensive in manufactured inputs (e.g., agrochemicals in modern agriculture). An additional advantage is making full use of the available information by taking into account the remaining value added coefficients of RPA.

In order to make comparisons among methods possible, all methods will be set according to the primary-input content of value of production, that is, the so-called "flow

${ }^{6}$ If using stocks, the total value of capital invested in RPA would have to be split between reproducible and non-reproducible capital.

${ }^{7}$ Strictly speaking, Postner (1975,p. 11) assumed constant "physical" coefficients and defined $\gamma$ accordingly. 
method" (Lary, 1968; Balassa, 1979). Vanek's method may be implemented by reassigning all rows corresponding to RPA from $\mathbf{A}$ to $\mathbf{F}$, and eliminating the corresponding columns. An equivalent to Postner's method is obtained by imputing a fixed rent coefficient $\gamma$ to all RPA and deducting it from the gross operating surplus coefficient of the corresponding activity. The result would be the original A matrix and a modified $\mathbf{F}^{\mathrm{P}}$ matrix for primary inputs. Finally, in the GOSRPA method an additional line in $\mathbf{F}$ registers the gross operating surpluses of the RPA, thus obtaining a modified $\mathbf{F}^{\text {gos }}$ matrix. Summing up, only Vanek's method results in a different A matrix, while all methods require an additional row in the $\mathbf{F}$ matrix containing the selected proxy for the direct rent content.

It is now possible to present the main differences among methods formally assuming that there are only four primary inputs: imports, labor, natural resources and capital. This is a simplification, since in practice there could be other primary inputs and transfers that would affect the calculation of total primary input contents, and thus affect primary input ratios. The approach, however, allows for a clear comparison of the three methods providing an approximation to their effects on primary input ratios.

The true, unknown, total primary input requirements of activity $j$ will be represented by

$$
1=\rho_{j}^{*}+w_{j}^{*}+k_{j}^{*}+m_{j}^{*}
$$

where $\rho_{j}^{*}, w_{j}^{*}, k_{j}^{*}$ and $m_{j}^{*}$ are, respectively, the correct total requirements of rents, wages, annual capital costs, and imports needed to produce $j$.

Total primary-input requirements of nonRPA $j$ calculated according to Vanek's method may be represented by

$$
1=n_{j}^{*}+w_{j}^{* V}+g_{j}^{* V}+m_{j}^{* V}
$$

where $n_{j}^{*}, w_{j}^{* V}, g_{j}^{* V}$ and $m_{j}^{* V}$ are, respectively, the total requirements of RP, wages, gross operating surplus, and imports. Superscript $V$ indicates the method. Note that the 
indirect requirements of wages, gross operating surplus and imports originate exclusively in nonresource inputs used in the production of nonRP. Total value requirements of RP may be expressed as the sum of their unknown total primary-input content as follows:

$$
n_{j}^{*}=\sum_{i \in N} n_{i j}^{*} \rho_{i}^{*}+\sum_{i \in N} n_{i j}^{*} w_{i}^{*}+\sum_{i \in N} n_{i j}^{*} k_{i}^{*}+\sum_{i \in N} n_{i j}^{*} m_{i}^{*}
$$

where $n_{i j}^{*}$ is the total requirement of RPA $i(i \in N)$ needed to produce a unit value of production of nonRPA $j(j \notin N)$. Total rent requirements may in turn be split into those originating in RPA and those from nonRPA. For example, $\rho_{i}^{*}$ may be expressed as

$$
\rho_{i}^{*}=\sum_{h \in N} r_{h i} \rho_{h}+\sum_{h \notin N} r_{h i} \rho_{h}
$$

where $r_{h i}$ is the total requirement of input $h$ used in the production of $i$, and $\rho_{h}$ is the corresponding direct rent content. ${ }^{8}$ The second term, $\Sigma_{h \notin N} r_{h i} \rho_{h}$, is the total rent content originating in nonresource inputs (e.g., the rent of the land where the plant producing $h$ is located). Using equations equivalent to (8) for all primary input requirements, and replacing them into (7) results in

$$
\begin{gathered}
n_{j}^{*}=\sum_{i \in N} n_{i j}^{*}\left[\left(\sum_{h \in N} r_{h i} \rho_{h}+\sum_{h \notin N} r_{h i} \rho_{h}\right)+\left(\sum_{h \in N} r_{h i} w_{h}+\sum_{h \notin N} r_{h i} w_{h}\right)+\right. \\
\left.\left(\sum_{h \in N} r_{h i} k_{h}+\sum_{h \notin N} r_{h i} k_{h}\right)+\left(\sum_{h \in N} r_{h i} m_{h}+\sum_{h \notin N} r_{h i} m_{h}\right)\right]
\end{gathered}
$$

This equation allows for the different methods to be presented formally, since they consist of different ways of allocating the information contained in (9).

The true total rent content of $j$ includes that originating in resource inputs $\left(\Sigma_{i \in N} r_{i j} \rho_{i}\right)$, as well as that originating in nonresource inputs $\left(\Sigma_{i \notin N} r_{i j} \rho_{i}\right)$. In practice, however, it is likely that the best possible estimate would only include rents originating in resource inputs. Rents from nonresource inputs will remain subsumed in the corresponding gross operating surpluses. Thus, in most situations the analyst will aim at estimating

\footnotetext{
${ }^{8}$ Note that coefficients $r_{h i}$ are those calculated with the original A matrix.
} 


$$
\begin{aligned}
& \rho_{j}^{*_{1}}=\rho_{j}^{*}-\sum_{i \notin N} r_{i j} \rho_{i}=\sum_{i \in N} r_{i j} \rho_{i} \\
& w_{j}^{*_{1}}=w_{j}^{*} \\
& g_{j}^{*_{1}}=k_{j}^{*}+\sum_{i \notin N} r_{i j} \rho_{i} \\
& m_{j}^{* \prime}=m_{j}^{*}
\end{aligned}
$$

The estimated rent coefficient $\rho_{j}^{*}$ would exclude those rents originating in nonresource inputs, rents that would be collected by the estimate of the capital-cost coefficient $g_{j}^{* \prime}$. This may be the best possible approximation in those cases where the most important rents originate in resource inputs.

Vanek's method may be represented using equations (8), (9) and (10):

$$
\begin{aligned}
& n_{j}^{*}=\text { equation }(8) \\
& w_{j}^{* V}=w_{j}^{*}-\sum_{i \in N} n_{i j}^{*}\left(\sum_{h \in N} r_{h i} w_{h}+\sum_{h \notin N} r_{h i} w_{h}\right) \\
& g_{j}^{* V}=k_{j}^{*}+\left(\sum_{i \notin N} r_{i j} \rho_{i}-\sum_{i \in N} n_{i j}^{*} \sum_{h \notin N} r_{h i} \rho_{h}\right)- \\
& \sum_{i \in N} n_{i j}^{*}\left(\sum_{h \in N} r_{h i} k_{h}+\sum_{h \notin N} r_{h i} k_{h}\right) \\
& m_{j}^{* V}=m_{j}^{*}-\sum_{i \in N} n_{i j}^{*}\left(\sum_{h \in N} r_{h i} m_{h}+\sum_{h \notin N} r_{h i} m_{h}\right)
\end{aligned}
$$

Rents are estimated by the total requirements of RP. Thus, the other primary-input requirements omit those originating in RP. In particular, gross operating surpluses of nonRPA would include only part of the rents originating in nonRPA, since total requirements of RPA capture part of those rents by including the total value of nonresource inputs for the production of RP.

Postner's method consists of using a constant rent coefficient $\gamma$ instead of the correct, but unknown $\rho_{i}$ : 


$$
\begin{aligned}
& \gamma_{j}^{*}=\sum_{i \in N} r_{i j} \rho_{i}+\sum_{i \in N} r_{i j}\left(\gamma-\rho_{i}\right) \\
& w_{j}^{* P}=w_{j}^{*} \\
& g_{j}^{* P}=k_{j}^{*}+\sum_{h \notin N} r_{i j} \rho_{i}-\sum_{i \in N} r_{i j}\left(\gamma-\rho_{i}\right) \\
& m_{j}^{* P}=m_{j}^{*}
\end{aligned}
$$

The constant $\gamma$ may be interpreted as an average of all $\rho_{i}(i \in N)$. It would provide a good approximation if it is a good estimate of that average and the dispersion of the $\rho_{i}$ around the average is small. For each activity, the error would be a weighted average of differences $\gamma-\rho_{i}$. Since direct coefficients often account for most of the total content, however, it is likely that the difference between $\gamma$ and the true direct content would determine the overall error for the activity estimate. Thus, the error in the distribution of estimated rent contents for all activity outputs would be greater the greater the variability of the direct rent coefficients $\rho_{i}$.

Finally, the measure proposed by Londero may be formally expressed as follows

$$
\begin{aligned}
& \rho_{j}^{* L}=\sum_{i \in N} r_{i j} \rho_{i}+\sum_{i \in N} r_{i j} k_{i} \\
& w_{j}^{* L}=w_{j}^{*} \\
& g_{j}^{* L}=k_{j}^{*}+\sum_{h \notin N} r_{i j} \rho_{i}-\sum_{i \in N} r_{i j} k_{i} \\
& m_{j}^{{ }^{*} L}=m_{j}^{*}
\end{aligned}
$$

The results of using this method would be more accurate the smaller the direct capital content of the RPA. For example, the more (reproducible) capital-intensive agriculture is, the greater the error would be; the more land-intensive with respect to capital cattle raising is, the smaller the error would be.

The preceding formulae for the primary input contents make it possible to compare the effects of different methods on the ratios between the primary input contents of each activity output. Consider, for example, the comparison of rent to labor ratios between the Postner and GOSRPA methods. Since both methods provide the same total 
wage content, the quotient between these two ratios would be

$$
\frac{\rho_{j}^{{ }^{L} L}}{\gamma_{j}^{*} \quad \sum_{i \in N} r_{i j} \rho_{i}+\sum_{i \in N} r_{i j}\left(\gamma-\rho_{i}\right)}
$$

The numerator is the total requirement of GOSRPA. The denominator is smaller than $\rho_{j}^{{ }^{*} L}$, since $\gamma$ is smaller than the smallest gross operating surplus coefficient of RPA $\left[\gamma<\min .\left(\rho_{i}+k_{i}, i \in N\right)\right]$. Thus, for any activity, rent to labor ratios calculated according to Postner's method would always be smaller than those calculated according to the GOSRPA method. Similarly, it may be concluded that rent to labor ratios of nonRPA calculated according to Vanek's method would always exceed those according to the GOSRPA method. Overall, for any activity $j$ the following relationships will be observed

$$
\begin{aligned}
& n_{j}^{*} / w_{j}^{* V}>\rho_{j}^{* L} / w_{j}^{* L}>\gamma_{j}^{*} / w_{j}^{* P} \\
& g_{j}^{* V} / w_{j}^{* V} \geq \leq \text { all others; } g_{j}^{* P} / w_{j}^{* P}>g_{j}^{* L} / w_{j}^{* L} \\
& g_{j}^{* P} / \gamma_{j}^{*}>g_{j}^{* L} / \rho_{j}^{* L}>g_{j}^{* V} / n_{j}^{*}
\end{aligned}
$$

That is, rent-labor and capital-rent ratios may be unambiguously ordered for all four methods. That is not so with capital to labor ratios, where only two measures can be ordered without reference to the data, since Vanek's method provides smaller capital and wage requirements than any other.

\section{Implications}

The three methods discussed in this paper share some common shortcomings. First, there is an implicit assumption that only RPA pay rents. While it may be true for most countries that in nonRPA the share of rents in the total value of production is very small, the assumption should be made explicit and its plausibility defended. The classification of an output as a "resource product" is also difficult in the cases of more capital intensive, primary sector activities like hog or chicken raising. As for their rent content, it is not 
apparent whether they are more similar to wheat production or to wheat milling.

Second, not all rents originate in natural resources associated to agriculture, forestry, or mining. In many countries, other natural resources or man made unique characteristics are important sources of rent. The export of tourism services is an example. Also, exports of some services by Panama may have a high rent content derived from the proximity to the Panama Canal.

The comparison of the three methods has shown that the Postner and the GOSRPA methods make a better use of the available information at a minimal extra cost. Therefore, these two methods should be preferred to Vanek's in empirical studies of the primary-input content of trade.

At the level of individual product estimates, equation (12) shows that Postner's method would provide a better approximation to the best estimate represented by equation (10) if the dispersion of rent coefficients of RPA is small, and if a good estimate of the average rent content $\gamma$ can be obtained. On the other hand, if rent coefficients of RPA show a high variability, and gross operating surplus coefficients vary with them (direct capital contents of RPA are low and similar), equation (13) shows that the GOSRPA method would be better able to capture that variability, and thus the differences in rent content among RPA outputs.

Some studies are more interested in the primary input composition of aggregate exports and imports, as was the case of Leontief $(1953,1956)$ and Postner (1975). It could be concluded that in such cases, Postner's method would provide a better approximation if the average rent content of RPA could be estimated using aggregate data, since $\gamma$ may be interpreted as such average. However, such average would be a weighted average of activity coefficients using production weights, rather than the correct export weights.

Special care should be exercised when making product or aggregate comparisons of primary input contents between countries, whichever of the two preferred methods is used. When using Postner's method, results will be sensitive to the values of $\gamma$ in each country, and there may be important differences amongst countries in the true average 
rent coefficients. These differences would themselves reflect the different factor endowments. For example, for a given product, direct rent coefficients would be expected to be lower and direct capital coefficients higher in a country where the particular resource is less abundant. In such case, therefore, comparisons of rent content based on the GOSRPA method would also be affected, leading to a greater overestimation of the rent content in the resource poor country.

Finally, from the data gathering perspective, it is possible to collect or improve the collection of capital stock data at the establishment level, distinguishing between reproducible and nonreproducible assets. Such data would be useful to improve rent estimates by either imputing rent and capital use, or splitting gross operating surplus coefficients.

\section{Conclusions}

Vanek's method underutilizes the available information. Postner's and GOSRPA methods make a better use of the information, since they account for the current inputs used in the production of RP, and should therefore be preferred over Vanek's. Preference of one over the other should be based on the expected variability of rent coefficients and the capital intensity of RPA.

In most cases it may be known without resorting to the data whether the primary input ratio of an activity output calculated according to one method is higher than the same ratio, for the same activity, but calculated according to another method. Therefore, it is possible to have some sense of the source of differences among studies using different methods.

Finally, the size of the differences between ratios calculated according to different methods will depend on the coefficients of the I-O table, and thus on the country studied. Empirical studies would be necessary to shed light on the practical implications of using different methods. 


\section{References}

Balassa, B., 1979. "A 'Stages' Approach to Comparative Advantage". In I. Adelman (ed.), Economic Growth and Resources: Proceedings of the Fifth World Congress of the International Economic Association, Vol. 4, St. Martin's Press, New York.

Deardorff, A., 1984. "Testing Trade Theories and Predicting Trade Flows". In R. Jones and P. Kenen (eds.), Handbook of International Economics, Vol. 1, North-Holland, Amsterdam.

Lary, H., 1968. Imports of Manufactures form Less Developed Countries. Columbia University Press, New York.

Leamer, E., and J. Levinsohn, 1994. "International Trade Theory: The Evidence". NBER Working Paper No. 4940. National Bureau of Economic Research, Washington DC.

Leontief, W., 1953. "Domestic Production and Foreign Trade: The American Capital Position Re-examined", Proceedings of the American Philosophical Society 97, 332-49.

Leontief, W., 1956. "Factor Proportions and the Structure of American Trade: Further Theoretical and Empirical Analysis", Review of Economics and Statistics 38, 386-407.

Londero, E. (1998), "Methodology". In Londero, Teitel et al. (1998).

Londero, E., and S. Teitel, 1996. "Industrialization and the Factor Content of Latin American Exports of Manufactures", Journal of Development Studies 32, 581-601.

Londero, E., S. Teitel et al., 1998. Resources, Industrialization and Exports in Latin America. Macmillan and St. Martin's, London and New York.

Postner, H., 1975. Factor Content of Canadian International Trade: An Input-Output Analysis. Economic Council of Canada, Ottawa.

Vanek, J., 1963. The Natural Resource Content of United States Foreign Trade, 18701955. MIT Press, Cambridge (Mass.). 